\title{
Hyperglycemia induced by pasireotide in patients with Cushing's disease or acromegaly
}

\author{
Julie M. Silverstein ${ }^{1}$
}

Published online: 12 July 2016

(c) The Author(s) 2016. This article is published with open access at Springerlink.com

\begin{abstract}
Purpose Cushing's disease (CD) and acromegaly are characterized by excessive hormone secretion resulting in comorbidities such as impaired glucose metabolism, diabetes and hypertension. Pasireotide is a new-generation, multireceptor-targeted somatostatin receptor ligand approved for CD (subcutaneous [SC] injection formulation) and acromegaly (long-acting release [LAR] formulation). In clinical studies of pasireotide, hyperglycemiarelated adverse events (AEs) were frequently observed. This review highlights differences in reported rates of hyperglycemia in pasireotide trials and discusses risk factors for and management of pasireotide-associated hyperglycemia.

Methods Clinical trials evaluating pasireotide in patients with CD or acromegaly were reviewed.

Results The frequency of hyperglycemia-related AEs was lower in patients with acromegaly treated with pasireotide LAR (57.3-67.0 \%) than in patients with CD treated with pasireotide SC (68.4-73.0 \%). Fewer patients with acromegaly treated with pasireotide LAR discontinued therapy because of hyperglycemia-related AEs (Colao et al. in J Clin Endocrinol Metab 99(3):791-799, 2014, $3.4 \%$; Gadelha et al. in Lancet Diabetes Endocrinol 2(11):875-884, 2014, $4.0 \%$ ) than did patients with CD treated with pasireotide SC (Boscaro et al. in Pituitary 17(4):320-326, 2014, 5.3 \%; Colao et al. in N Engl J Med
\end{abstract}

Julie M. Silverstein

jsilvers@dom.wustl.edu

1 Division of Endocrinology, Metabolism and Lipid Research, Washington University School of Medicine, St Louis, MO, USA
366(10):914-924, 2012, 6.0\%). Hyperglycemia-related AEs occurred in $40.0 \%$ of patients with acromegaly treated with pasireotide SC, and $10.0 \%$ discontinued treatment because of hyperglycemia. Ongoing studies evaluating pasireotide LAR in patients with CD and management of pasireotide-induced hyperglycemia in patients with $\mathrm{CD}$ or acromegaly (ClinicalTrials.gov identifiers NCT01374906 and NCT02060383, respectively) will address these key safety issues.

Conclusions Disease pathophysiology, drug formulation, and physician experience potentially influence the differences in reported rates of pasireotide-induced hyperglycemia in CD and acromegaly. Hyperglycemic effects associated with pasireotide have a predictable pattern, can be managed with antidiabetic agents, and are reversible upon discontinuation.

Keywords Acromegaly · Cushing's disease · Hyperglycemia $\cdot$ Pasireotide

\section{Introduction}

Cushing's disease (CD) and acromegaly are rare diseases characterized by the increased production of adrenocorticotropic hormone (ACTH) in the former and growth hormone $(\mathrm{GH})$ in the latter [1]. In $\mathrm{CD}$, hypercortisolemia is caused by the secretion of ACTH from a corticotroph pituitary tumor. In acromegaly, GH excess, most commonly from a somatotroph pituitary tumor, causes downstream hypersecretion of insulin-like growth factor 1 (IGF1). Chronic elevation of cortisol (CD) and GH and IGF-1 (acromegaly) levels is associated with increased mortality risk and worsening comorbidities in both conditions [1,2]. Thus, in both diseases, the treatment goals include 
normalization of hormone levels, reversal of clinical features, prevention of disease recurrence, and reduction in tumor volume in cases of pituitary macroadenomas $[1,3]$.

Surgery is considered first-line treatment and provides adequate control of cortisol levels in many patients with CD (65-90\%) [4] and GH and IGF-1 levels in patients with acromegaly (microadenomas, $>85 \%$; macroadenomas, 40-50\%) [3]. Despite the success rates associated with surgery, $5-10 \%$ of patients with CD [4] and 2-8\% of patients with acromegaly [3] will experience disease recurrence within 5 years after achieving postoperative hormone remission. Medical therapy (sometimes used as a bridge until adjuvant radiation therapy has taken full effect) is an option for patients with recurrent or persistent $\mathrm{CD}$ or acromegaly following surgery.

Pasireotide is a new-generation, multireceptor-targeted somatostatin receptor ligand (SRL) approved for the treatment of patients with $\mathrm{CD}$ (subcutaneous [SC] formulation) [5] or acromegaly (long-acting release [LAR] formulation) [6]. It is indicated for patients who do not achieve control with surgery and/or for whom surgery is not an option [5, 6]. Pasireotide binds to several known somatostatin receptor (sst) subtypes that are expressed by corticotroph and somatotroph tumors, resulting in decreased secretion of ACTH and GH, respectively. Both corticotroph and somatotroph tumors express relatively high levels of sst $_{2}$ and sst $_{5}$ [7]. Compared with octreotide, pasireotide binds with higher affinity to $\mathrm{sst}_{1}$ (30-fold), $\mathrm{sst}_{3}$ (5-fold), and $\mathrm{sst}_{5}$ (39-fold) and lower affinity to $\mathrm{sst}_{2}$ (3fold) $[8,9]$. Pasireotide also binds with higher affinity than lanreotide to $\mathrm{sst}_{1}$ (19-fold), $\mathrm{sst}_{3}$ (9-fold), and $\mathrm{sst}_{5}$ (106-fold) but with lower affinity to $s_{2} t_{2}$ (2-fold) [8]. The combination of the broad binding profile of pasireotide with its preferential binding to sst $_{5}$ provides therapeutic rationale for its use in the treatment of $\mathrm{CD}$ and acromegaly. Although its efficacy in clinical studies has warranted consideration of pasireotide as the first treatment of choice among SRLs, the effect of pasireotide on glucose metabolism should be considered when choosing the best SRL option for each patient [10]. This review provides a summary of data from clinical studies and case reports that document hyperglycemia-related adverse events (AEs) associated with pasireotide in patients with either acromegaly or CD.

\section{Clinical efficacy of pasireotide in CD and acromegaly}

\section{Pasireotide SC in CD}

In a phase 3 study of 162 patients with persistent or recurrent $\mathrm{CD}$ or newly diagnosed disease, who were not eligible for surgery, twice-daily injections of pasireotide
$\mathrm{SC}$ provided rapid reductions in mean levels of urinary-free cortisol (UFC) that were sustained during treatment [11]. After 12 months of pasireotide 600 and $900 \mu \mathrm{g}$ twice daily, 13 and $25 \%$ of patients achieved UFC levels at or below the upper limit of the normal range, respectively. At 12 months, tumor volume reductions were also observed with $600 \mu \mathrm{g}(-9.1 \%)$ and $900 \mu \mathrm{g}(-43.8 \%)$. Decreases in mean UFC were associated with improved signs and symptoms of disease, including systolic blood pressure (mean change from baseline, $-6.1 \mathrm{~mm} \mathrm{Hg}$ ), diastolic blood pressure (mean change from baseline, $-3.7 \mathrm{~mm} \mathrm{Hg}$ ), weight (mean change from baseline, $-6.7 \mathrm{~kg}$ ), and healthrelated quality-of-life score (mean change from baseline, 11.1 points). Improvements in facial rubor and supraclavicular and dorsal fat pads were also reported. In addition, $69 \%$ of patients $(\mathrm{n}=11)$ who remained in the study for 60 months achieved UFC levels at or below the upper limit of the normal range [12].

\section{Pasireotide in acromegaly}

In a phase 3 study of patients with acromegaly who were naive to medical therapy, significantly more patients achieved biochemical control $(\mathrm{GH}<2.5 \mathrm{ng} / \mathrm{mL}$ and ageand sex-adjusted IGF-1) after 1 year of monthly injections of pasireotide LAR $40 \mathrm{mg}$ than after 1 year of monthly injections of octreotide LAR $20 \mathrm{mg}$ (31.3 vs $19.2 \%$ ) [13]. Tumor volume reductions were similar between the 2 treatment groups (pasireotide LAR, $40 \%$; octreotide LAR, $38 \%$ ), and both therapies improved symptoms of disease (e.g., perspiration, fatigue, osteoarthralgia, paresthesia, headache) and quality of life.

In another phase 3 study that enrolled patients with acromegaly who were inadequately controlled by other SRLs, monthly injections of pasireotide LAR $40 \mathrm{mg}$ $(15 \%)$ and $60 \mathrm{mg}(20 \%)$ provided greater biochemical control than the active control treatment (octreotide LAR $30 \mathrm{mg}$ or lanreotide Autogel $120 \mathrm{mg} ; 0 \%$ ) at 6 months [14]. Furthermore, more patients in the pasireotide LAR 40 and $60-\mathrm{mg}$ groups achieved tumor volume reductions of $>25 \%$ than did those in the active control group (18.5 and $10.8 \%$ vs $1.5 \%$ ). Improvements in symptom severity scores also occurred at higher degrees in patients in the pasireotide LAR 40 and 60-mg groups than in those in the active control group. Symptoms included headache, fatigue, perspiration, paresthesia, and osteoarthralgia.

The efficacy and safety of pasireotide SC in acromegaly have also been investigated. In a phase 2 extension study, $33 \%$ of patients ( 3 of 9 ) achieved biochemical control after 24 months of treatment [15]. Up to $75 \%$ of patients who responded to treatment demonstrated tumor volume reductions of $\geq 20 \%$. Additionally, the number of patients showing improvements in symptoms of disease (i.e., 
headache, fatigue, perspiration, osteoarthralgia) approximately doubled during the course of the study.

\section{Hyperglycemia associated with pasireotide in CD and acromegaly}

\section{Clinical trials experience}

In clinical trials, the safety profile of pasireotide included AEs, mostly related to gastrointestinal symptoms and cholelithiasis, that were largely consistent with other SRLs $[5,6]$. However, compared with other SRLs, treatment with pasireotide is associated with a higher frequency of hyperglycemia in patients with CD or acromegaly $[11,13,14]$. The reported rates of hyperglycemia-related AEs and the percentage of patients who discontinued therapy from such events differ across clinical studies of pasireotide in CD and acromegaly (Table 1). Further comparison of the rates shows that the frequency of hyperglycemia-related AEs was lower in patients with acromegaly who received pasireotide LAR $(57.3-67.0 \%)$ [13, 14] than in patients with CD who received pasireotide SC (68.4-73.0\%) [11, 16]. Interestingly, fewer patients with acromegaly who received pasireotide LAR discontinued treatment because of hyperglycemia-related AEs, as reported in 2 separate trials (3.4 and $4.0 \%),[13,14]$ compared with patients with CD who received pasireotide $\mathrm{SC}$, also as reported in 2 separate trials $(6.0$ and $5.3 \%)[11,16]$. In a clinical study that evaluated the efficacy and safety of pasireotide SC in acromegaly, hyperglycemia-related AEs occurred in $40.0 \%$ of patients, and $10.0 \%$ of patients discontinued treatment because of such events [15].
Several underlying factors could contribute to differences in the reported frequency of pasireotide-induced hyperglycemia among patients with $\mathrm{CD}$ or acromegaly. In clinical studies of acromegaly, the rates of pasireotide-induced hyperglycemia-related AEs were lower than those in CD (Fig. 1a). This could be related to disease pathophysiology since the dysregulation of glucose metabolism in $\mathrm{CD}$ and acromegaly could be uniquely linked to downstream effects associated with chronic exposure to elevated levels of cortisol or GH/IGF-1, respectively [17, 18]. Also, because studies of pasireotide in CD occurred before those in acromegaly, the benefit of physician experience could have led to lower rates of study discontinuation in the acromegaly trials (Fig. 1b). This could be attributed to a better understanding of the mechanisms underlying pasireotide-induced hyperglycemia and its optimal management in patients with acromegaly or CD. Despite the higher frequency of hyperglycemia-related AEs associated with pasireotide than with other medical therapies for acromegaly or $\mathrm{CD}$, results from other clinical studies suggest that the hyperglycemic effect associated with treatment has a predictable pattern, can be managed with antidiabetic medications (ADM), and is reversible upon discontinuation of treatment with pasireotide.

\section{Mechanisms of pasireotide-induced hyperglycemia}

It has been reported that impaired glucose metabolism observed in patients with $\mathrm{CD}$ or acromegaly is uniquely associated with disease pathophysiology. Chronic exposure to elevated GH and IGF-1 levels is associated with insulin resistance, which may be counteracted by the compensatory hyperfunction of pancreatic beta cells in patients

Table 1 Hyperglycemia-related AEs associated with pasireotide in clinical studies of Cushing's disease or acromegaly

\begin{tabular}{|c|c|c|c|c|c|c|}
\hline Study & Disease & $\begin{array}{l}\text { Study } \\
\text { description }\end{array}$ & $\begin{array}{l}\text { Study } \\
\text { duration }\end{array}$ & Drug formulation (dosing) & $\begin{array}{l}\text { Hyperglycemia- } \\
\text { related AEs }\end{array}$ & $\begin{array}{l}\text { Discontinuations due to } \\
\text { hyperglycemia-related AEs } \\
(\%)\end{array}$ \\
\hline $\begin{array}{l}\text { Colao } \\
\text { et al. } \\
{[11]}\end{array}$ & $\begin{array}{l}\text { Cushing's } \\
\text { disease }\end{array}$ & Phase 3 & 12 months & Pasireotide SC $(600,900 \mu \mathrm{g}$ b.i.d $)$ & $73.0 \%$ & 6.0 \\
\hline $\begin{array}{l}\text { Boscaro } \\
\text { et al. } \\
{[16]}\end{array}$ & $\begin{array}{l}\text { Cushing's } \\
\text { disease }\end{array}$ & $\begin{array}{l}\text { Phase 2, } \\
\text { extension }\end{array}$ & 6 months & $\begin{array}{l}\text { Pasireotide SC ( } 600 \mu \mathrm{g} \text { b.i.d; } 900 \mu \mathrm{g} \\
\text { with suboptimal control) }\end{array}$ & $68.4 \%$ & 5.3 \\
\hline $\begin{array}{l}\text { Colao } \\
\text { et al. } \\
{[13]}\end{array}$ & Acromegaly & Phase 3 & 12 months & $\begin{array}{l}\text { Pasireotide LAR ( } 40 \mathrm{mg} \text {; dose increase } \\
\text { to } 60 \mathrm{mg} \text { with suboptimal control) }\end{array}$ & $57.3 \%$ & 3.4 \\
\hline $\begin{array}{l}\text { Gadelha } \\
\text { et al. } \\
\text { [14] }\end{array}$ & Acromegaly & Phase 3 & $\begin{array}{l}6 \text { months } \\
\text { or } \\
\text { longer }\end{array}$ & Pasireotide LAR $(40,60 \mathrm{mg})$ & $\begin{array}{l}40 \mathrm{mg}, 67.0 \% \\
60 \mathrm{mg}, 61.0 \%\end{array}$ & 4.0 \\
\hline $\begin{array}{l}\text { Petersenn } \\
\text { et al. } \\
\text { [15] }\end{array}$ & Acromegaly & $\begin{array}{l}\text { Phase } 2 \text {, } \\
\text { extension }\end{array}$ & $\begin{array}{l}6 \text { months } \\
\text { or } \\
\text { longer }\end{array}$ & $\begin{array}{l}\text { Pasireotide SC (200, 400, } 600 \mu \mathrm{g} \text {; } \\
900 \mu \mathrm{g} \text { with suboptimal control) }\end{array}$ & $40.0 \%$ & 10.0 \\
\hline
\end{tabular}

$A E$ adverse event, b.i.d twice daily, $L A R$ long-acting release, $S C$ subcutaneous 

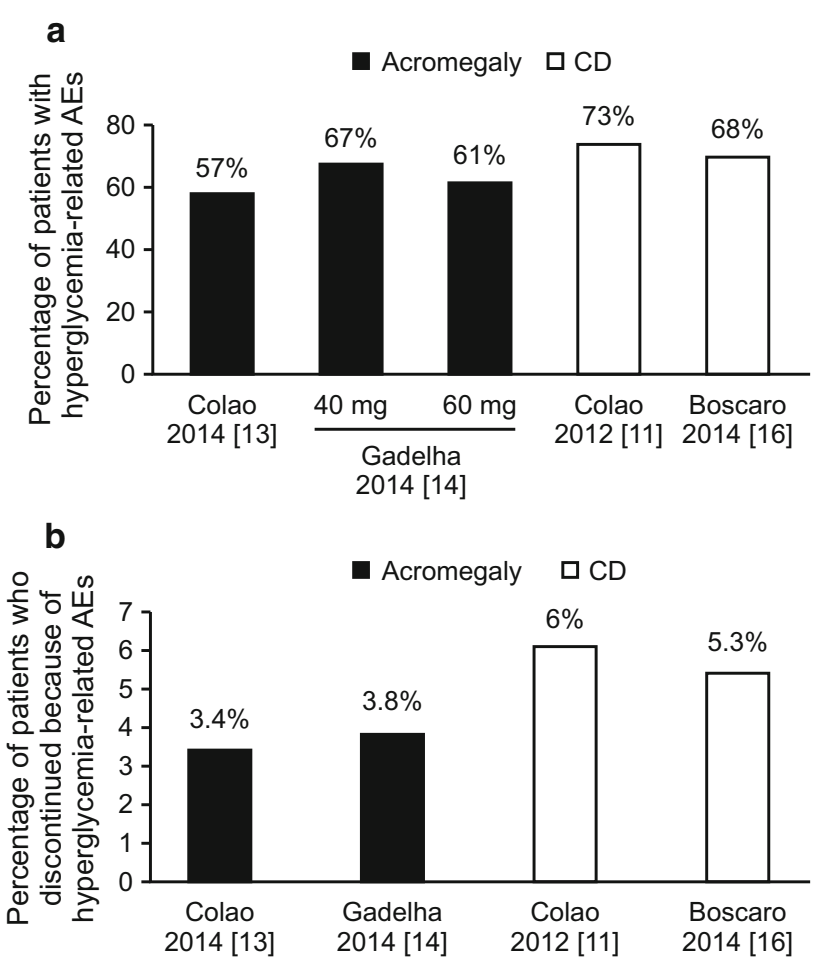

Fig. 1 Factors potentially affecting reported differences in a the frequency of pasireotide-induced hyperglycemia and $\mathbf{b}$ the frequency of discontinuations associated with hyperglycemia among patients with $\mathrm{CD}$ or acromegaly. $A E$ adverse event, $C D$ Cushing's disease, $L A R$ long-acting release, $S C$ subcutaneous. Figure was created with Adobe Illustrator CC 2015

with acromegaly with normal glucose tolerance [18]. Similarly, in CD, chronic hypercortisolism blocks the binding of insulin to peripheral tissues, resulting in insulin resistance, and inhibits the release of insulin by pancreatic beta cells [17]. Excess cortisol can also affect glucose metabolism in hepatic tissue by stimulating gluconeogenesis or indirectly inhibiting insulin sensitivity by depleting storage of hepatic glycogen.

Recently, there has been a greater understanding of the mechanisms that underlie the development of hyperglycemia in patients with acromegaly or CD treated with pasireotide. The hyperglycemic effects of pasireotide are primarily due to its tendency to reduce insulin and incretin secretion [19]. Insulin secretion is mediated in large part by sst $_{2}$ and sst $_{5}$ [20, 21], and glucagon secretion is mediated primarily by sst $_{2}[21,22]$. Pasireotide binds to sst $_{2}$ and sst $_{5}$ and binds with highest affinity to sst $_{5}$, which is expressed not only by pituitary cells but also by other cell types. For example, pasireotide binds to sst $_{5}$ in pancreatic islet cells, which leads to reduced insulin secretion that is not observed with SRLs that bind to $\mathrm{sst}_{2}$ with greater affinity $[19,23]$. Reduced insulin levels associated with pasireotide are unable to counterbalance the reduced insulin sensitivity caused by uncontrolled acromegaly or CD [18]. However, two mechanisms could explain why the hyperglycemic effect is transient. First, pasireotide has minimal effects on glucagon secretion and no effects on insulin sensitivity in healthy volunteers [19]. In contrast, octreotide and lanreotide suppress glucagon secretion, which could be due to increased binding of $\mathrm{sst}_{2}[21,22]$, a key mediator of glucagon secretion to which octreotide and lanreotide bind with greater affinities than pasireotide [8]. By improving biochemical control, it is likely that insulin sensitivity will increase, which should improve glucose tolerance, even if insulin secretion remains reduced. Second, it was reported that levels of IGF-binding protein 2 increased after 24 weeks of pasireotide LAR [24], which could attenuate the long-term hyperglycemic effects of pasireotide LAR.

\section{Levels of fasting plasma glucose and glycated hemoglobin during treatment course}

Fasting plasma glucose (FPG) and glycated hemoglobin $\left(\mathrm{HbA}_{1 \mathrm{c}}\right)$ levels are parameters used to assess glycemic control [25]. In a clinical study of patients with acromegaly, it was reported that up to $45 \%$ of patients with baseline FPG between 100 and $126 \mathrm{mg} / \mathrm{dL}$ had FPG levels $\geq 126 \mathrm{mg} / \mathrm{dL}$ after 26 months of pasireotide LAR [26]. In a clinical study of patients with CD treated with pasireotide, worsened diabetic status was observed in $76 \%$ of patients who had normal $\mathrm{HbA}_{1 \mathrm{c}}$ levels at baseline [27]. During the course of treatment in patients with acromegaly or $\mathrm{CD}$, mean FPG levels peaked after 1 month of pasireotide and thereafter remained stable or slightly decreased [11, 12, 14, 26-28]. In some patients, levels of FPG and $\mathrm{HbA}_{1 \mathrm{c}}$ were stabilized during the course of treatment with pasireotide LAR for up to 26 months [26, 27]. These observations suggest that pasireotide initially induces an increase in FPG and $\mathrm{HbA}_{1 \mathrm{c}}$ levels, which then stabilize during the course of treatment.

\section{Predictive risk factors of pasireotide-induced hyperglycemia}

In $\mathrm{CD}$, the prevalence of impaired glucose tolerance or diabetes mellitus at diagnosis is $21-64 \%$ and $20-47 \%$, respectively [29]. Similarly, the prevalence of impaired fasting glucose and diabetes are higher in patients with acromegaly compared with the general population, predisposing patients to a greater risk of developing hyperglycemia [30]. This suggests that baseline glycemic status before the initiation of pasireotide treatment could be predictive of the extent and severity of hyperglycemia associated with treatment. In a phase 3 study of patients with acromegaly, baseline FPG $>100 \mathrm{mg} / \mathrm{dL}$ correlated with the development of higher FPG and $\mathrm{HbA}_{1 \mathrm{c}}$ levels and a higher degree of hyperglycemia during pasireotide LAR 
treatment [24]. Moreover, it was reported that increasing the dose of pasireotide LAR from 40 to $60 \mathrm{mg}$ was associated with a 21-36\% increased risk of developing hyperglycemia [31, 32]. Regarding disease control as a predictive factor, reductions in GH and IGF-1 in patients with newly diagnosed acromegaly who were treated with octreotide for 6 months without ADM were shown to correlate with change in $\mathrm{HbA}_{1 \mathrm{c}}$ levels [33]; however, a similar association in patients treated with pasireotide has not yet been studied. Other predictive risk factors associated with developing hyperglycemia in patients with acromegaly treated with pasireotide LAR include body mass index $\geq 25 \mathrm{~kg} / \mathrm{m}^{2}$, diabetes at baseline, and history of dyslipidemia [34]. Because certain populations are at greater risk of hyperglycemia associated with pasireotide, proactive management and monitoring of these patients are critical for improving clinical outcomes.

\section{Management of pasireotide-induced hyperglycemia}

\section{Optimal treatment with ADMs}

As previously discussed, in phase 3 studies of pasireotide $\mathrm{SC}$ in CD and pasireotide LAR in acromegaly, the majority of hyperglycemia-related AEs were mild to moderate in severity $[11,13,14]$. Even in patients with acromegaly with FPG $>250 \mathrm{mg} / \mathrm{dL}$ at baseline, ADM initiated within 2 weeks of the first dose of pasireotide LAR led to rapid decreases in FPG, suggesting that early treatment intervention with ADMs could optimally manage pasireotideinduced hyperglycemia [34]. Metformin has been shown to be minimally effective in reducing pasireotide-induced hyperglycemia in healthy volunteers [35]; however, this study measured effects on glucose metabolism after only 6 days, which may have been too brief to observe longterm effects of metformin. For instance, metformin has been shown to increase glucagon-like peptide 1 (GLP-1) [36], which may at least partially compensate for the reduction in GLP-1 associated with pasireotide [19]. Antidiabetic medication, primarily metformin, was administered in $38-48 \%$ of patients in acromegaly trials $[13,14,26]$. Mean $\mathrm{HbA}_{1 \mathrm{c}}$ levels in patients with acromegaly naive to medical therapy who developed pasireotideinduced hyperglycemia were $<7 \%$ after 12 months when treated with metformin alone or in combination with other ADMs [37]. A case study of a patient with CD exemplified that control of hyperglycemia could be achieved with metformin in combination with glipizide and sitagliptin [38]. These results suggest that metformin is useful for some patients in treating pasireotide-associated hyperglycemia.
In some case study reports, treatment with metformin alone was insufficient in providing glycemic control to patients with pasireotide-induced hyperglycemia [39-41]. In these cases, treatment with insulin alone or glipizide with or without insulin was able to quickly reduce FPG levels. Dietary control or modification could also be important for management of pasireotide-induced hyperglycemia [16, 42]. In healthy volunteers who were administered pasireotide SC, coadministration with liraglutide, a GLP-1 agonist, was most effective in reducing serum glucose levels ( $72 \%$ lower than with pasireotide alone) [35]. Coadministration with vildagliptin, a dipeptidyl peptidase-4 (DPP-4) inhibitor, was most effective in attenuating the reduction in serum insulin levels (71\% higher than with pasireotide alone). These studies indicate that by following standard guidelines for the treatment of diabetes and adapting treatment with ADMs on the basis of each patient's glycemic status, pasireotide-induced hyperglycemia can be effectively managed.

\section{Treatment recommendations}

Medical expert recommendations have been established for the management of pasireotide-induced hyperglycemia in patients with CD [17, 43]. In patients not currently treated with insulin, and particularly for those with insulin resistance, it is recommended that metformin be initiated or continued if FPG $>126 \mathrm{~g} / \mathrm{dL}$ or $\mathrm{HbA}_{1 \mathrm{c}}$ is $>6.5 \%$ [43]. In cases in which patients fail to achieve glycemic control with metformin, it is suggested that a DPP-4 inhibitor be added. A GLP-1 receptor agonist should replace the DPP-4 inhibitor if $\mathrm{HbA}_{1 \mathrm{c}}$ remains $>7.0 \%$. If neither DPP-4 inhibitors nor GLP-1 receptor agonists provide glucose control, it is suggested that treatment with insulin be initiated while maintaining metformin treatment. Although no specific recommendations regarding pasireotide-induced hyperglycemia in patients with acromegaly have been published, treatment with metformin plus a DPP-4 inhibitor, GLP-1 agonist, or insulin would most likely have similar efficacy.

\section{Monitoring recommendations}

Patients with CD or acromegaly who initiate, discontinue, or need dose adjustment of pasireotide should be proactively managed in accordance with current monitoring guidelines and recommendations. Levels of FPG and $\mathrm{HbA}_{1 \mathrm{c}}$ should be evaluated before initiation of treatment, and blood glucose should be monitored weekly for the first 2-3 months after initiation and for the first 2-6 weeks after a dose increase [5, 6]. Similarly, medical expert opinion also recommends that, in patients with normal glucose 
metabolism prior to initiating pasireotide, fasting and postprandial glucose levels should be monitored several times per day, twice during the first week, and once weekly thereafter [17, 43]. Moreover, patients with abnormal glucose metabolism during treatment should be monitored daily upon initiating pasireotide and while adjusting treatment as necessary to optimally control glycemic levels $[5,6,17,43]$. If warranted, dose reduction or discontinuation of pasireotide should be implemented if hyperglycemia is not controllable despite medical management $[5,6]$. It is suggested that FPG and $\mathrm{HbA}_{1 \mathrm{c}}$ levels of patients who discontinue pasireotide may need to be assessed frequently to reduce the risk of developing hypoglycemia.

\section{Reversibility of hyperglycemia upon discontinuation of pasireotide}

Clinical studies of pasireotide in healthy volunteers and in patients with $\mathrm{CD}$ or acromegaly suggest that the hyperglycemic effects associated with pasireotide have a predictable pattern and could be effectively managed by following recommended guidelines set forth by expert opinions [5, 6, 17, 43]. Moreover, deterioration in glycemic status associated with pasireotide is reversible upon treatment discontinuation, which potentially restores glycemic parameters to normoglycemic levels [44]. The reversibility of the hyperglycemic effects of pasireotide has been shown in a pharmacokinetic analysis of single-dose administration, in which mean glucose levels increased to $\geq 200 \mu \mathrm{g}$ and then normalized $23 \mathrm{~h}$ after injection [45]. In a previous case study, normalization of glycemic levels was demonstrated in a patient who discontinued pasireotide SC because of lack of response to treatment [44]. In a phase 3 clinical trial of patients with acromegaly who were treated with pasireotide, mean FPG and mean $\mathrm{HbA}_{1 \mathrm{c}}$ levels were reduced to $104 \mathrm{mg} / \mathrm{dL}$ (mean value at baseline, $127 \mathrm{mg} /$ $\mathrm{dL}$ ) and to $6.12 \%$ (mean value at baseline, $6.71 \%$ ), respectively, within 3 months of switching from pasireotide LAR to octreotide LAR [28]. In conclusion, hyperglycemia associated with pasireotide is transient and not expected to cause long-term effects if pasireotide is discontinued.

\section{Conclusions}

Pasireotide is a viable medical therapy option for patients with $\mathrm{CD}$ or acromegaly but is associated with higher rates of hyperglycemia and diabetes mellitus than other medical therapies. Further research is needed to determine optimal treatment strategies with ADMs to achieve glycemic control in patients with pasireotide-induced hyperglycemia.
For example, a multivariate analysis could be performed of baseline FPG and $\mathrm{HbA}_{1 \mathrm{c}}$ levels across clinical studies of pasireotide in $\mathrm{CD}$ or acromegaly to further assess the predictability and manageability of pasireotide-induced hyperglycemia. A phase 4 study is currently ongoing that will evaluate the effects of incretin-based therapy compared with insulin on glycemic control at 16 weeks in patients with $\mathrm{CD}$ or acromegaly (ClinicalTrials.gov identifier NCT02060383) [46]. Significant progress has been made over the years to better understand the mechanisms by which impaired glucose metabolism in patients is uniquely linked to the disease pathophysiology of $\mathrm{CD}$ and acromegaly and how pasireotide modulates insulin secretion and sensitivity. There is growing evidence to demonstrate that proactive management with ADMs can effectively manage hyperglycemia-related AEs associated with pasireotide during the course of treating patients with CD or acromegaly.

Acknowledgments Assistance with medical writing and editing was provided under the direction of the authors by Paul Cao and Meredith MacPherson, MedThink SciCom, Inc, with support from Novartis Pharmaceuticals Corporation.

Funding Financial support was provided by Novartis Pharmaceuticals Corporation.

\section{Compliance with ethical standards}

Conflict of interest JMS has received research support from Ipsen Biopharmaceuticals, Inc, Novartis Pharmaceuticals Corporation, Novo Nordisk, and Pfizer. She is on the speaker's bureau for Pfizer and Chiasma and has been on an advisory board for Chiasma, Ipsen Biopharmaceuticals, and Corcept.

Ethical approval This article does not contain any studies with human participants or animals performed by any of the authors.

Open Access This article is distributed under the terms of the Creative Commons Attribution 4.0 International License (http://crea tivecommons.org/licenses/by/4.0/), which permits unrestricted use, distribution, and reproduction in any medium, provided you give appropriate credit to the original author(s) and the source, provide a link to the Creative Commons license, and indicate if changes were made.

\section{References}

1. Biller BM, Colao A, Petersenn S, Bonert VS, Boscaro M (2010) Prolactinomas, Cushing's disease and acromegaly: debating the role of medical therapy for secretory pituitary adenomas. BMC Endocr Disord 10:10

2. Holdaway IM, Rajasoorya RC, Gamble GD (2004) Factors influencing mortality in acromegaly. J Clin Endocrinol Metab 89(2):667-674

3. Katznelson L, Laws ER Jr, Melmed S, Molitch ME, Murad MH, Utz A, Wass JA (2014) Endocrine society: acromegaly: an endocrine society clinical practice guideline. J Clin Endocrinol Metab 99(11):3933-3951 
4. Biller BM, Grossman AB, Stewart PM, Melmed S, Bertagna X, Bertherat J, Buchfelder M, Colao A, Hermus AR, Hofland LJ, Klibanski A, Lacroix A, Lindsay JR, Newell-Price J, Nieman LK, Petersenn S, Sonino N, Stalla GK, Swearingen B, Vance ML, Wass JA, Boscaro M (2008) Treatment of adrenocorticotropindependent Cushing's syndrome: a consensus statement. J Clin Endocrinol Metab 93(7):2454-2462

5. Signifor [package insert]. East Hanover, NJ: Novartis Pharmaceuticals Corporation (2012)

6. Signifor LAR [package insert]. East Hanover, NJ: Novartis Pharmaceuticals Corporation (2014)

7. Hofland LJ, Lamberts SW (2003) The pathophysiological consequences of somatostatin receptor internalization and resistance. Endocr Rev 24(1):28-47

8. Bruns C, Lewis I, Briner U, Meno-Tetang G, Weckbecker G (2002) SOM230: a novel somatostatin peptidomimetic with broad somatotropin release inhibiting factor (SRIF) receptor binding and a unique antisecretory profile. Eur $\mathrm{J}$ Endocrinol 146(5):707-716

9. Hofland LJ, van der Hoek J, Feelders R, van Aken MO, van Koetsveld PM, Waaijers M, Sprij-Mooij D, Bruns C, Weckbecker G, de Herder WW, Beckers A, Lamberts SW (2005) The multiligand somatostatin analogue SOM230 inhibits ACTH secretion by cultured human corticotroph adenomas via somatostatin receptor type 5. Eur J Endocrinol 152(4):645-654

10. Chanson P (2016) Medical treatment of acromegaly with dopamine agonists or somatostatin analogs. Neuroendocrinology 103(1):50-58

11. Colao A, Petersenn S, Newell-Price J, Findling JW, Gu F, Maldonado M, Schoenherr U, Mills D, Salgado LR, Biller BM (2012) Pasireotide B2305 Study Group: a 12-month phase 3 study of pasireotide in Cushing's disease. N Engl J Med 366(10):914-924

12. Petersenn S, Salgado LR, Schopohl J, Portocarrero-Ortiz L, Arnaldi G, Lacroix A, Ravichandran S, Kandra A, Biller BMK (2015) Long-term (5 years) treatment of Cushing's disease with pasireotide. In: Poster presented at: European congress of endocrinology 2015, May 16-20, Dublin, Ireland

13. Colao A, Bronstein MD, Freda P, Gu F, Shen CC, Gadelha M, Fleseriu M, van der Lely AJ, Farrall AJ, Hermosillo Resendiz K, Ruffin M, Chen Y, Sheppard M (2014) Pasireotide C2305 Study Group: pasireotide versus octreotide in acromegaly: a head-tohead superiority study. J Clin Endocrinol Metab 99(3):791-799

14. Gadelha MR, Bronstein MD, Brue T, Coculescu M, Fleseriu M, Guitelman M, Pronin V, Raverot G, Shimon I, Lievre KK, Fleck J, Aout M, Pedroncelli AM, Colao A (2014) Pasireotide C2402 Study Group: pasireotide versus continued treatment with octreotide or lanreotide in patients with inadequately controlled acromegaly (PAOLA): a randomised, phase 3 trial. Lancet Diabetes Endocrinol 2(11):875-884

15. Petersenn S, Farrall AJ, De Block C, Melmed S, Schopohl J, Caron P, Cuneo R, Kleinberg D, Colao A, Ruffin M, Hermosillo Resendiz K, Hughes G, Hu K, Barkan A (2014) Long-term efficacy and safety of subcutaneous pasireotide in acromegaly: results from an open-ended, multicenter, phase II extension study. Pituitary 17(2):132-140

16. Boscaro M, Bertherat J, Findling J, Fleseriu M, Atkinson AB, Petersenn S, Schopohl J, Snyder P, Hughes G, Trovato A, Hu K, Maldonado M, Biller BM (2014) Extended treatment of Cushing's disease with pasireotide: results from a 2-year, phase II study. Pituitary 17(4):320-326

17. Colao A, De Block C, Gaztambide MS, Kumar S, Seufert J, Casanueva FF (2014) Managing hyperglycemia in patients with Cushing's disease treated with pasireotide: medical expert recommendations. Pituitary 17(2):180-186

18. Kasayama S, Otsuki M, Takagi M, Saito H, Sumitani S, Kouhara H, Koga M, Saitoh Y, Ohnishi T, Arita N (2000) Impaired beta- cell function in the presence of reduced insulin sensitivity determines glucose tolerance status in acromegalic patients. Clin Endocrinol (Oxf) 52(5):549-555

19. Henry RR, Ciaraldi TP, Armstrong D, Burke P, Ligueros-Saylan M, Mudaliar S (2013) Hyperglycemia associated with pasireotide: results from a mechanistic study in healthy volunteers. J Clin Endocrinol Metab 98(8):3446-3453

20. Fagan SP, Azizzadeh A, Moldovan S, Ray MK, Adrian TE, Ding X, Coy DH, Brunicardi FC (1998) Insulin secretion is inhibited by subtype five somatostatin receptor in the mouse. Surgery 124(2):254-258 discussion 258-259

21. Singh V, Brendel MD, Zacharias S, Mergler S, Jahr H, Wiedenmann B, Bretzel RG, Plockinger U, Strowski MZ (2007) Characterization of somatostatin receptor subtype-specific regulation of insulin and glucagon secretion: an in vitro study on isolated human pancreatic islets. J Clin Endocrinol Metab 92(2):673-680

22. Singh V, Grotzinger C, Nowak KW, Zacharias S, Goncz E, Pless G, Sauer IM, Eichhorn I, Pfeiffer-Guglielmi B, Hamprecht B, Wiedenmann B, Plockinger U, Strowski MZ (2007) Somatostatin receptor subtype-2-deficient mice with diet-induced obesity have hyperglycemia, nonfasting hyperglucagonemia, and decreased hepatic glycogen deposition. Endocrinology 148(8):3887-3899

23. Kumar U, Sasi R, Suresh S, Patel A, Thangaraju M, Metrakos P, Patel SC, Patel YC (1999) Subtype-selective expression of the five somatostatin receptors (hSSTR1-5) in human pancreatic islet cells: a quantitative double-label immunohistochemical analysis. Diabetes 48(1):77-85

24. Schmid HA, Brue T, Colao A, Gadelha M, Shimon I, Kapur K, D'Amoato L, Pedroncelli AM, Fleseriu M (2014) Effect of pasireotide on GH, IGF-1, IGFBP-2, IGFBP-3, HbA1c and glucose in patients with inadequately controlled acromegaly: exploratory results from a multicentre, randomized, 24-week study (PAOLA). In: Poster presented at: European congress of endocrinology 2014; May 3-7, Wrcoclaw, Poland

25. American Diabetes Association (2015) Glycemic targets. Sec. 6. In: Standards of Medical Care in Diabetes 2015. Diabetes Care. 38(Suppl. 1):S33-S40

26. Sheppard M, Bronstein MD, Freda P, Serri O, De Marinis L, Naves L, Rozhinskaya L, Hermosillo Resendiz K, Ruffin M, Chen Y, Colao A (2015) Pasireotide LAR maintains inhibition of GH and IGF-1 in patients with acromegaly for up to 25 months: results from the blinded extension phase of a randomized, doubleblind, multicenter, phase III study. Pituitary 18(3):385-394

27. Schopohl J, Gu F, Rubens R, Van Gaal L, Bertherat J, LiguerosSaylan M, Trovato A, Hughes G, Salgado LR, Boscaro M, Pivonello R (2015) Pasireotide B2305 Study Group: pasireotide can induce sustained decreases in urinary cortisol and provide clinical benefit in patients with Cushing's disease: results from an open-ended, open-label extension trial. Pituitary 18(5):604-612

28. Freda P, Fleseriu M, van der Lely AJ, Colao A, Sheppard M, Gu F, Shen C-C, Gadelha M, Farrall AJ, Hermosillo Resendiz K, Ruffin M, Chen Y, Bronstein MD (2013) Switching patients with acromegaly from octreotide LAR to pasireotide LAR improves biochemical control: crossover extension to a randomized, double-blind, multicenter, phase III study. In: Poster presented at: European congress of endocrinology 2013; April 27-May 1, Copenhagen, Denmark

29. Feelders RA, Pulgar SJ, Kempel A, Pereira AM (2012) The burden of Cushing's disease: clinical and health-related quality of life aspects. Eur J Endocrinol 167(3):311-326

30. Dreval AV, Trigolosova IV, Misnikova IV, Kovalyova YA, Tishenina RS, Barsukov IA, Vinogradova AV, Wolffenbuttel BH (2014) Prevalence of diabetes mellitus in patients with acromegaly. Endocr Connect 3(2):93-98

31. Shen G, Darstein C, Hermosillo Resendiz K, Hu K (2014) Pharmacokinetic and pharmacodynamic analyses of pasireotide 
LAR and octreotide LAR: randomized, double-blind, phase III study in patients with medically naïve acromegaly. In: Poster presented at: European congress of endocrinology 2014, May 3-7, Wroclaw, Poland

32. Shen G, Darstein C, Hermosillo Resendiz K, Hu K (2015) Analysis of pharmacokinetic (PK) and pharmacodynamic (PD) data for efficacy and safety from a randomized phase III study of pasireotide LAR in patients with acromegaly inadequately controlled on first-generation somatostatin analogs (SSA). In: Poster presented at: Endocrine society annual meeting 2015; March 5-8, San Diego, CA

33. Helseth R, Carlsen SM, Bollerslev J, Svartberg J, Øksnes M, Skeie S, Fougner SL (2016) Preoperative octreotide therapy and surgery in acromegaly: associations between glucose homeostasis and treatment response. Endocrine 51(2):298-307

34. Gadelha M, Brue T, Fleseriu M, Shimon I, Hermosillo Resendiz K, Kandra A, Perdoncelli AM, Colao A (2015) Proactive monitoring and early intervention in the management of pasireotideinduced hyperglycemia: lessons from the phase III, 24-week PAOLA study. In: Poster presented at: Endocrine society annual meeting 2015; March 5-8, San Diego, CA

35. Breitschaft A, Hu K, Hermosillo Resendiz K, Darstein C, Golor G (2014) Management of hyperglycemia associated with pasireotide (SOM230): healthy volunteer study. Diabetes Res Clin Pract 103(3):458-465

36. Kim MH, Jee JH, Park S, Lee MS, Kim KW, Lee MK (2014) Metformin enhances glucagon-like peptide 1 via cooperation between insulin and Wnt signaling. J Endocrinol 220(2):117-128

37. Colao A, Gu F, Gadelha MR, van der Lely AJ, Fleseriu M, Passos VQ, Ravichandran S, Chen Y, Bronstein MD (2015) Metforminbased oral antidiabetic therapy is effective at controlling hyperglycemia associated with pasireotide in patients with acromegaly. In: Poster presented at: Endocrine society annual meeting 2015; March 5-8, San Diego, CA

38. Shimon I, Rot L, Inbar E (2012) Pituitary-directed medical therapy with pasireotide for a corticotroph macroadenoma: pituitary volume reduction and literature review. Pituitary 15(4):608-613
39. Mercado J, Moloney K, Ludlam WH, Broyles F (2013) Sustained improvements in clinical status and quality of life in a patient with recurrent Cushing's disease treated with pasireotide. In: Poster presented at: American association of clinical endocrinologists 22nd annual scientific and clinical congress; May 1-5, Phoenix, AZ

40. Mercado J, Moloney K, Ludlam WH, Broyles F (2013) Oral antidiabetic management of hyperglycemia in a patient with Cushing's disease treated with pasireotide: a case study. In: Poster presented at: American association of clinical endocrinologists 22nd annual scientific and clinical congress; May 1-5, Phoenix, AZ

41. Broyles F, Ludlam WH, Mayberg M (2014) Successful long-term management of refractory Cushing's disease with pasireotide: a case report. In: Poster presented at: Endocrine society annual meeting 2014; May 14-18, Las Vegas, NV

42. Lu L, Duan L, Jin Z, Lu Z, Gu F (2013) Effective long-term treatment of Cushing's disease with pasireotide: a case report. Endocr Pract 19(4):e92-e96

43. Reznik Y, Bertherat J, Borson-Chazot F, Brue T, Chanson P, Cortet-Rudelli C, Delemer B, Tabarin A, Bisot-Locard S, Verges B (2013) Management of hyperglycaemia in Cushing's disease: experts' proposals on the use of pasireotide. Diabetes Metab 39(1):34-41

44. MacKenzie Feder J, Bourdeau I, Vallette S, Beauregard H, SteMarie LG, Lacroix A (2014) Pasireotide monotherapy in Cushing's disease: a single-centre experience with 5-year extension of phase III trial. Pituitary 17(6):519-529

45. Golor G, Hu K, Ruffin M, Buchelt A, Bouillaud E, Wang Y, Maldonado M (2012) A first-in-man study to evaluate the safety, tolerability, and pharmacokinetics of pasireotide (SOM230), a multireceptor-targeted somatostatin analog, in healthy volunteers. Drug Des Devel Ther 6:71-79

46. Gu F, Ravichandran S, Tseng L, Subramanian A, Chen Y, Schofl C (2015) Management of pasireotide-induced hyperglycemia in patients with Cushing's disease or acromegaly: study design of a randomized, open-label, phase IV trial. In: Poster presented at: Endocrine society annual meeting 2015, March 5-8, San Diego, CA 